\title{
Titanocene Pnictinidene Complexes
}

Dr. Malte Fischer, ${ }^{[a]}$ Dr. Fabian Reiß, ${ }^{*[a]}$ Dr. Christian Hering-Junghans* ${ }^{[a]}$

${ }^{[a]}$ Dr. M. Fischer, Dr. F. Reiß, Dr. C. Hering-Junghans

Leibniz-Institut für Katalyse e.V. (LIKAT Rostock)

Albert-Einstein-Straße 29a, 18059 Rostock, Germany

E-Mail: fabian.reiss@catalysis.de; christian.hering-junghans@catalysis.de

\begin{abstract}
The phospha-Wittig reagent MesTerPPMe ${ }_{3}$ (MesTer $=2,6-\left\{2,4,6-\mathrm{Me}_{3}-\mathrm{C}_{6} \mathrm{H}_{2}\right\}-\mathrm{C}_{6} \mathrm{H}_{3}$ ) and arsa-Wittig reagent ${ }^{\text {Dip TerAsPMe }} 3$ ( ${ }^{\text {Dip Ter }}=2,6-\left\{2,6-i \mathrm{Pr}_{2}-\mathrm{C}_{6} \mathrm{H}_{3}\right\}-\mathrm{C}_{6} \mathrm{H}_{3}$ ) have been employed to synthesize the titanocene complexes $\mathrm{Cp}_{2} \mathrm{Ti}\left(\mathrm{PMe}_{3}\right) \operatorname{PnAr}(\mathrm{Pn}=\mathrm{P}, \mathrm{As})$ with terminal phosphinidene or arsinidene ligands, respectively. Ab initio studies show that the description as singlet biradicaloids in their ground state is warranted.
\end{abstract}

\section{Introduction}

Phosphinidenes, the isovalence-electronic P-analogous of carbenes, are in contrast to the stable and widely applied $\mathrm{N}$-heterocyclic carbenes (NHCs), ${ }^{1-3}$ or cyclic alkyl amino carbenes (cAACs) $)^{4} 5$ mostly transient species that need to be stabilized through e.g. coordination to a transition metal fragment, ${ }^{6}$ or by cycloaddition reactions to (conjugated) multiple bond systems as was recently shown for RP(anthracene) systems. ${ }^{7}$ Just recently, the first example of a free kinetically stabilized phosphinophosphinidene has been reported by Bertrand et al. ${ }^{8}$ Together with free phosphinidenes, terminal phosphinidene complexes of the type $\left[L_{n} M=P R\right]$ are highly desirable compounds to access a carbene-like chemistry for phosphorus-element bond 
formation and phosphinidene-transfer reactions. ${ }^{9-12}$ Nucleophilic phosphinidene complexes are preferred when the spectator ligands $L$ are strong $\sigma$-donors, while strong $\pi$-accepting ligands render the phosphinidene unit more electrophilic. ${ }^{13}$ In contrast to the rich chemistry of phosphinidene-bridged dinuclear complexes, ${ }^{14}$ terminal phosphinidene complexes are rare and Mindiola et al. used sterically demanding $\beta$-diketiminate supporting ligands on titanium to access terminal phosphinidenes (Scheme 1, i and ii). Oxidation of a dimethyl complex with AgOTf and subsequent addition of LiP(H)Tip (Tip = 2,4,6-iPr $\mathrm{Cr}_{6} \mathrm{H}_{2}$ ) furnished $\left[\left({ }^{\left({ }_{B} \mathrm{~N}\right.} \mathrm{Nacnac}\right)(\mathrm{Me}) \mathrm{Ti}=\mathrm{PTip}\right] \quad\left(\mathbf{I},{ }^{\mathrm{BBu}} \mathrm{Nacnac}=\mathrm{CH}(\mathrm{C}(t \mathrm{Bu}) \mathrm{NDip})_{2} ;\right.$ Dip $\left.=2,6-i \mathrm{Pr}_{2} \mathrm{C}_{6} \mathrm{H}_{3}\right)$ with concomitant release of methane and LiOTf. ${ }^{15}$ [( $\left.\left.{ }^{\mathrm{MeNacnac}}\right)\left(\mathrm{CH}_{2}{ }^{\mathrm{t}} \mathrm{Bu}\right) \mathrm{Ti}=\mathrm{PMes}{ }^{*}\right]$ (II, $\left.{ }^{\text {Me Nacnac }}=\mathrm{CH}\left(\mathrm{C}\left(\mathrm{CH}_{3}\right) \mathrm{NDip}\right)_{2 i} ; \mathrm{Mes}^{*}=2,4,6-\mathrm{Bu}_{3} \mathrm{C}_{6} \mathrm{H}_{2}\right)$ was prepared from a putative neopentaylidene phosphide via a 1,3-H-shift of the $\alpha$-hydrogen (Scheme 1, ii). ${ }^{16}$ The same synthetic strategy was utilized to synthesize a $\mathrm{Ti}(\mathrm{IV})$ phosphinidene complex bearing a monoanionic PNP-pincer ligand. ${ }^{17}$ Reaction of the Ti(II) synthon $\left[\mathrm{CpTi}\left(\mathrm{NP}(t \mathrm{tBu})_{3}\right)\left(\mathrm{CH}_{2}\right)_{4}\right]$ with $\mathrm{Mes}^{*} \mathrm{PH}_{2}$ in the presence of $\mathrm{PMe}_{3}$ afforded the corresponding base-stabilized complex $\left.\left[(\mathrm{Cp})\left(\mathrm{NP}(t \mathrm{Bu})_{3}\right)\left(\mathrm{PMe}_{3}\right) \mathrm{Ti}=\mathrm{PMes}^{*}\right)\right](\mathrm{III})$, which showed three characteristic resonances in the ${ }^{31} \mathrm{P}$ NMR spectrum at $\delta\left({ }^{31} \mathrm{P}\right)=769.9,35.3$, and $-10.3 \mathrm{ppm}$ for the phosphinidene, phosphinimide, and $\mathrm{PMe}_{3}$ phosphorus, respectively (Scheme 1, iii). ${ }^{18}$

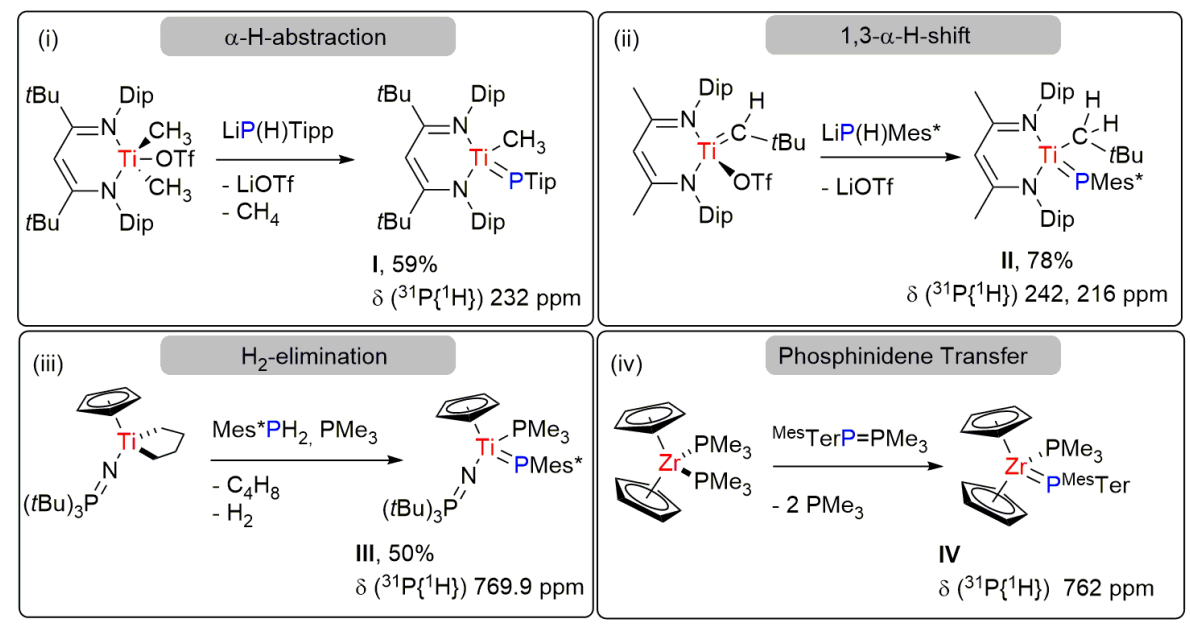

Scheme 1. Reported syntheses of selected group 4 phosphinidene complexes with the respective ${ }^{31} \mathrm{P}$ NMR shifts of the phosphinidene units. 
Efficient transfer of a PAr unit can also be achieved by so-called phospha-Wittig reagents of the general type $\mathrm{ArP}=\mathrm{PMe}_{3}{ }^{19}$ The combination of the $\mathrm{Zr}(\mathrm{II})$ synthon $\left[\mathrm{Cp}_{2} \mathrm{Zr}\left(\mathrm{PMe}_{3}\right)_{2}\right]$ and ${ }^{\text {Mes TerPPMe}} 3$ ( ${ }^{\text {Mes Ter }}=2,6-\mathrm{Mes}_{2} \mathrm{C}_{6} \mathrm{H}_{3}, \quad$ Mes $\left.=2,4,6-\mathrm{Me}_{3} \mathrm{C}_{6} \mathrm{H}_{2}\right)$ afforded $\left[(\mathrm{Cp})_{2}\left(\mathrm{PMe}_{3}\right) \mathrm{Zr}=\mathrm{P}^{\mathrm{Mes}} \mathrm{Ter}\right](\mathbf{I V})$ with a characteristic deshielded phosphinidene phosphorus with a ${ }^{31} \mathrm{P}$ NMR signal at $\delta\left({ }^{31} \mathrm{P}\right)=762 \mathrm{ppm}\left(\right.$ Scheme 1, iv) ${ }^{20}$

Recently, we attempted the synthesis of terminal titanocene phosphinidene complexes by treatment of the $\mathrm{Ti}(\mathrm{II})$ synthon $\left[\mathrm{Cp}_{2} \mathrm{Ti}\left(\right.\right.$ btmsa) (btmsa $=\mathrm{C}_{2}\left(\mathrm{SiMe}_{3}\right)_{2}{ }^{21}$ with aryl substituted triphosphiranes $\mathrm{P}_{3} \mathrm{Ar}_{3}(\mathrm{Ar}=\mathrm{Tip}$, Dip, Mes), which afforded the titanocene diphosphene complexes $\left[C p_{2} T i\left(P_{2} A_{2}\right)\right]$ instead. ${ }^{22}$ In this contribution we close this gap and introduce the synthesis and characterization of terminal titanocene phosphinidene and arsinindene complexes. The bonding has been thoroughly studied by combined DFT and $a b$ initio studies.

As a synthetic entry we chose the titanocene precursor [Cp $2 \mathrm{Ti}(\mathrm{btmsa})](\mathbf{1}){ }^{23,}{ }^{24}$ in combination with the phospha-Wittig reagents $\mathrm{Mes}^{\star} \mathrm{PPMe}_{3}(\mathbf{2} \mathbf{a}),{ }^{\mathrm{Mes}} \mathrm{TerPPMe}_{3}(\mathbf{2} \mathbf{b})$ and ${ }^{\mathrm{Dip} T e r P P M e} \mathbf{P}_{3}$ (2c) (Scheme 2). ${ }^{25}$ In analogy to the synthesis of IV using $\mathbf{2} \mathbf{b}$ in conjunction with $\mathrm{Cp}_{2} \mathrm{Zr}\left(\mathrm{PMe}_{3}\right)_{2}{ }^{20}$ we first studied the formal ligand exchange reaction btmsa for PAr between $\mathbf{1}$ and $\mathbf{2}$ to give [ $\mathrm{Cp}_{2} \mathrm{Ti}\left(\mathrm{PMe}_{3}\right) \mathrm{PAr}$ in-silico to evaluate its thermodynamic feasibility. For all three combinations an exergonic Gibbs Free Enthalpy change to give the complexes $\left.\left[\mathrm{Cp}_{2}\left(\mathrm{PMe}_{3}\right) \mathrm{Ti}=\mathrm{PAr}\right)\right]$ according to equation $1\left(\Delta_{\mathrm{R}} \mathrm{G}^{\theta}=-5.8(\mathbf{2} \mathbf{a}),-11.2\right.$ (2b), $-9.0(\mathbf{2 c}) \mathrm{kcal} \cdot \mathrm{mol}^{-1}$, Eq. 1, Table S4) was obtained. ${ }^{26}$

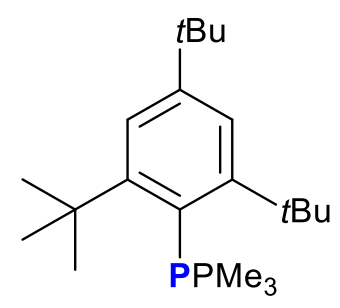

$2 \mathbf{a}$

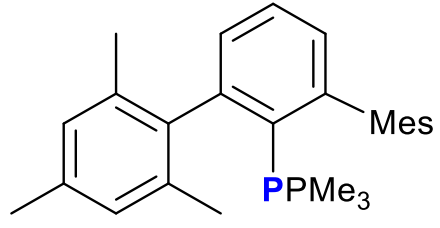

2b

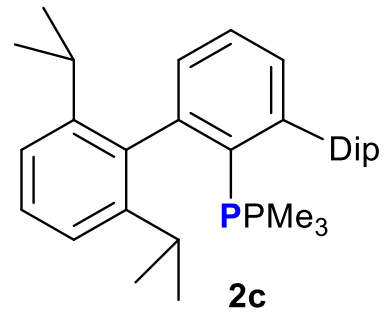

2c

Scheme 2. Phospha-Wittig reagents $\mathbf{2 a - c}$ utilized in this study. 
(Eq. 1) $\mathrm{ArPPMe}_{3}+\mathrm{Cp}_{2} \mathrm{Ti}($ btmsa $) \rightarrow \mathrm{Cp}_{2} \mathrm{Ti}\left(\mathrm{PMe}_{3}\right)(\mathrm{PAr})+$ btmsa

Then 1 and $\mathbf{2 a}$ were combined in $\mathrm{C}_{6} \mathrm{D}_{6}$. At room temperature no reaction was observed after $16 \mathrm{~h}$, but warming to $40^{\circ} \mathrm{C}$ resulted in the formation of the known 3,3-dimethyl5,7-di-tert-butylphosphaindane (A) (Figures S5-S7). ${ }^{18,26,27}$ This suggests phosphinidene release and formal insertion of the phosphinidene unit into a $\mathrm{C}-\mathrm{H}$-bond of one tertbutyl methyl group, which is faster than recombination with $\mathrm{Cp}_{2} \mathrm{Ti}$. Phosphaindane formation is reminiscent of the reaction of the stable phosphinidene complex $\left[{ }^{3 t} \mathrm{Cp}_{2}\right.$ UPMes* ${ }^{*}$ with diphenylacetylene, which resulted in the formation of $\mathbf{A}$ and $\left[{ }^{3 \mathrm{t}} \mathrm{Cp} \mathrm{p}_{2} \mathrm{U}\left(\mathrm{C}_{2} \mathrm{Ph}_{2}\right)\right] \cdot{ }^{28}$

In contrast, treatment of $\mathbf{1}$ with $\mathbf{2} \mathbf{b}$ on an NMR scale in $\mathrm{C}_{6} \mathrm{D}_{6}$ at $80{ }^{\circ} \mathrm{C}$ for $16 \mathrm{~h}$ resulted in the clean formation of a new species and complete consumption of both starting materials, accompanied by the release of btmsa $\left(\delta\left({ }^{1} \mathrm{H}\right)=0.15 \mathrm{ppm}\right)$. This new compound could be unambiguously characterized to be the $\mathrm{PMe}_{3}$ stabilized titanocene phosphinidene $\left[\mathrm{Cp}_{2}\left(\mathrm{PMe}_{3}\right) \mathrm{Ti}=\mathrm{P}^{\mathrm{Mes}} \mathrm{Ter}\right]$ (3) by combined spectroscopic methods (Scheme 3, top). An unsymmetrical coordination environment at titanium is indicated by two signals for the $\mathrm{Cp}_{2} \mathrm{Ti}$ unit $\left(\delta\left({ }^{1} \mathrm{H}\right)=5.22,5.23 \mathrm{ppm}\right)$ in the ${ }^{1} \mathrm{H}$ NMR spectrum and the signals of the terphenyl moiety are broadened, suggesting hindered rotation within the molecule. In the ${ }^{31} \mathrm{P}\left\{{ }^{1} \mathrm{H}\right\}$ NMR spectrum two diagnostic doublets $\left({ }^{2} J_{P, P}=21.7 \mathrm{~Hz}\right)$ at $\delta\left({ }^{31} \mathrm{P}\left\{{ }^{1} \mathrm{H}\right\}\right)=8.0\left(\mathrm{PMe}_{3}\right)$ and $1067.3(\mathrm{PTer}) \mathrm{ppm}\left(\delta_{\text {calc }}\left({ }^{31} \mathrm{P}\left\{{ }^{1} \mathrm{H}\right\}\right)=-41.3\left(\mathrm{PMe}_{3}\right) ; 1162.1\right.$ (PTer) ppm), respectively, were detected. ${ }^{26}$ The latter being significantly deshielded by ca. $300 \mathrm{ppm}$ compared to the titanium phosphinidene complex $\left.\left[(\mathrm{Cp})(\mathrm{NPtBu})\left(\mathrm{PMe}_{3}\right) \mathrm{Ti}=\mathrm{PMes} *\right)\right](\mathrm{III}$, Scheme 1$) .{ }^{18} \mathrm{X}$-ray quality intensely coloured brown crystals of $\mathbf{3}$ were obtained by slowly cooling a saturated toluene solution of $\mathbf{3}$ from $80{ }^{\circ} \mathrm{C}$ to room temperature (Figure 1 , left). The central titanium atom is in a trigonalpyramidal coordination environment according to $\tau_{4}=0.80 .{ }^{29}$ The Ti1-P1-C1 bond angle of $122.12(6)^{\circ}$ is significantly more bent as in structurally characterized I $\left(159.95(7)^{\circ}\right)[6]$ and II $\left(164.44(5)^{\circ}\right),{ }^{15}, 16$ respectively. Comparable base-stabilized titanium imido complexes of the general type $\left[\mathrm{Cp}_{2}(\mathrm{~L}) \mathrm{Ti}=\mathrm{N}^{\mathrm{Mes}} \mathrm{Ter}\right](\mathrm{L}=$ pyridine, $\mathrm{THF}$, $\mathrm{RCN}$ ) also show $\mathrm{Ti}-\mathrm{N}-\mathrm{C}_{\mathrm{Ter}}$ angles of over $155^{\circ} .{ }^{30}$ 


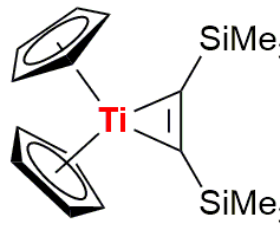

1

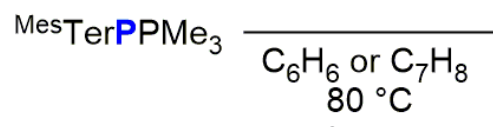

- btmsa

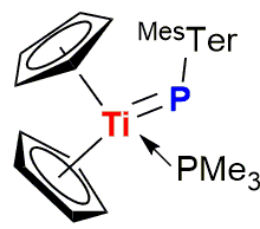

3

$2 b$

$\delta\left({ }^{31} \mathrm{P}\left\{{ }^{1} \mathrm{H}\right\}\right) 1067 \mathrm{ppm}$

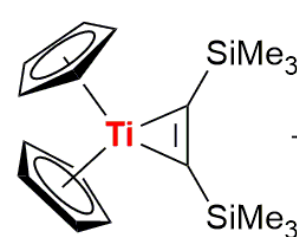

1
DipTerAsPMe 3

$80^{\circ} \mathrm{C}$

- btmsa

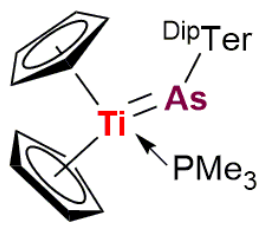

5

Scheme 3. Synthesis of the titanocene pnictinidene complexes $\mathbf{3}$ and $\mathbf{5}$.

The bent geometry at the phosphorus agrees with the analogous zirconium complex

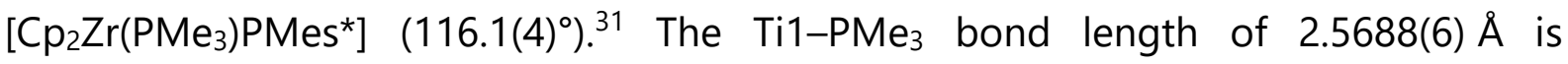
significantly longer than typical titanium phosphorus single bonds $\left(\sum r_{\mathrm{cov}}(\mathrm{Ti}-\right.$ P) $=2.47 \AA)^{32}$ and corresponds to dative bonding, whereas the Ti1-P1 bond length of 2.4225(6) $\AA$ is shortened but does not approach a double bond $\left(\sum r_{\operatorname{cov}}(P=P) 2.29 \AA\right){ }^{32}$ For both I (2.1644(7) $\AA$ ) and II (2.1831(4) $\AA$ ) significantly shorter titanium phosphorus bond lengths were found and result in pseudo-triply bonded systems. ${ }^{15}$, 16 Attempts to synthesize a base-free titanocene phoshinidene complex using phospha-Wittig

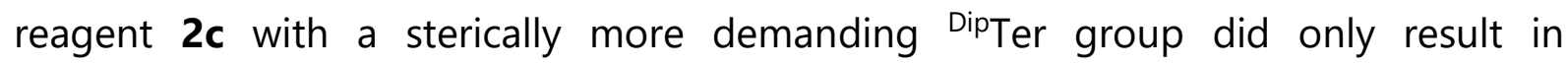
decomposition of $\mathbf{1}$ at higher temperatures. ${ }^{26}$

The successful isolation of $\mathbf{3}$ prompted us to test whether a terminal arsinidene complex is feasible as well. To date there are two potential arsa-Wittig reagents described in the literature, ${ }^{\mathrm{Tip}} \mathrm{TerAsPMe}{ }_{3}{ }^{33}$ and ${ }^{\mathrm{Dip}} \mathrm{TerAsPMe}_{3}(\mathbf{4}) .{ }^{34}$ Using an equimolar mixture of 4 and 1 in $C_{6} D_{6}$ at room temperature revealed a new signal in the ${ }^{31} \mathrm{P} N M R$ spectrum at $\delta\left({ }^{31} \mathrm{P}\right)=16.7 \mathrm{ppm}$ after $8 \mathrm{~h}$ at room temperature and after heating the mixture to $80^{\circ} \mathrm{C}$ over a period of $16 \mathrm{~h}$ full conversion of both $\mathbf{1}$ and $\mathbf{4}$ to the titanocene arsinidene complex $\left[\mathrm{Cp}_{2}\left(\mathrm{PMe}_{3}\right) \mathrm{Ti}=\mathrm{As}{ }^{\mathrm{Dip} T e r}\right]$ (5) was detected (Scheme 3, bottom). 

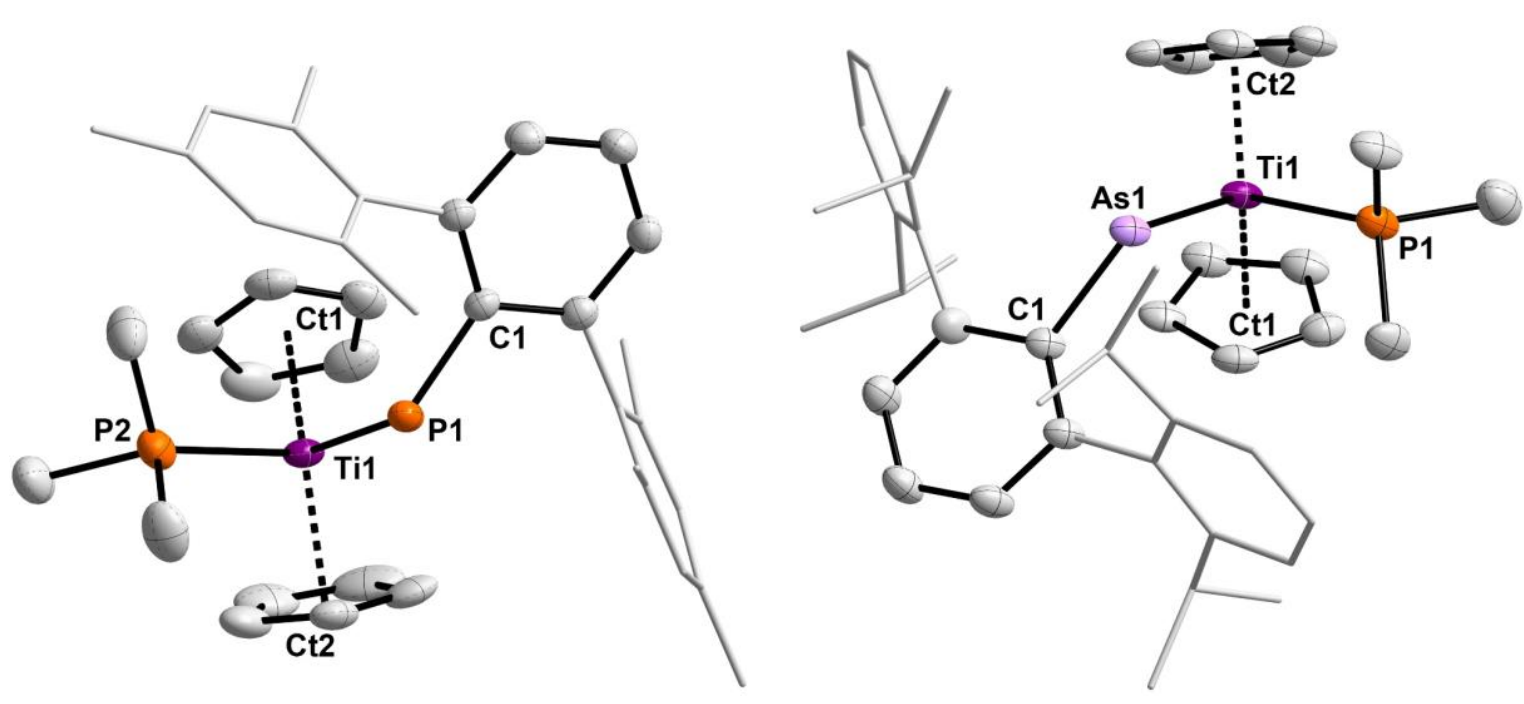

Figure 1. ORTEP drawing of the molecular structures of $\mathbf{3}$ (left) and $\mathbf{5}$ (right). Hydrogen atoms omitted for clarity and thermal ellipsoids drawn at 50\% (3) or 30\% (5) probability, respectively. ${ }^{26}$

We note that using sub-stoichiometric amounts of $\mathbf{1}$ in the reaction with $\mathbf{4}$ reproducibly gave rise to the formation of the diarsene ( $\left.{ }^{\mathrm{Dip} T e r A s}\right)_{2}(\mathbf{6})$ as a side product. We independently showed that heating 4 to $105^{\circ} \mathrm{C}$ in $\mathrm{C}_{6} \mathrm{D}_{6}$ over a period of $130 \mathrm{~h}$ afforded 6 quantitively based on ${ }^{1} \mathrm{H}$ NMR spectroscopy and recrystallization from $n$-pentane at $-30^{\circ} \mathrm{C}$ allowed the isolation of 6 in $54 \%$ yield as a yellow crystalline solid and two modifications were identified by SC-XRD experiments (Figures S3 and S4). Attempts to crystallize $\mathbf{5}$ proved difficult, however, from saturated $n$-hexane solutions $X$-ray quality deep brown crystals of $\mathbf{5}$ could reproducibly be grown at $-30{ }^{\circ} \mathrm{C} .{ }^{26} \mathbf{5}$ crystallizes in the triclinic spacegroup $P-1$ with three independent molecules in the asymmetric unit (Figure S2). As in $\mathbf{3}$, the value of $\tau_{4}=0.80$ is diagnostic of a trigonal-pyramidal coordination environment at titanium, ${ }^{29}$ with a similar Ti1-As1-C1 bond angle of $121.73(10)^{\circ}$ (cf. $3122.12(6)^{\circ}$ ) and corresponds to four electron donation from the arsinidene ligand to Ti (Figure 1, right). Transition metal complexes with an arsinidene ligand are rare and the herein reported $\mathbf{5}$ is the first arsinidene complex of a group 4 metal. Wolczanski et al. synthesized the first transition metal arsinidene complex $(t \mathrm{BuSiO})_{3} \mathrm{Ta}=\mathrm{AsPh}$ with a Ta-As-C bond angle of $107.2(4)^{\circ}$ and a Ta-As bond length of $2.428(2) \AA\left(\sum r_{\operatorname{cov}}(\mathrm{Ta}=\mathrm{As}) 2.40 \AA\right),{ }^{32,35}$ not approaching a double bond according to the 
covalent radii, which is also true for $\mathbf{5}$ with a Ti1-As1 bond length of 2.4726(8) $\AA$ $(\mathrm{Ti}-\mathrm{As}$ avg $2.4674 \AA)\left(\sum r_{\operatorname{cov}}(\mathrm{Ti}=\mathrm{As}) 2.31 \AA \text {, (Ti-As) } 2.57 \AA\right)^{32}$ indicative of a weak $\pi$ component within this bond. It is worth mentioning that other structurally characterized arsinidene complexes were reported bearing tungsten, ${ }^{36}$ iron, $^{37}$ and uranium metal centers. ${ }^{38}$

To gain a better understanding of the bonding situation in $\mathbf{3}$ and $\mathbf{5}$ we first performed an NBO analysis of the B3LYP/GD3BJ/def2tzvp optimized structures to analyse the natural localized molecular orbitals (NLMO) ${ }^{26}$ This revealed a double bond between P1 and Ti1, in agreement with the Lewis structure in Scheme 3, however, both the $\pi$-type NBO as well as the LP at P1 are occupied by only 1.8 electrons, indicating a delocalized $\mathrm{Ti}=\mathrm{P}$ double bond or a potential biradical character. Nevertheless, NLMO analysis is consistent with a $\mathrm{Ti}=\mathrm{P}$ double bond, which consists of a classical $\mathrm{sp}^{3}-\mathrm{d} \sigma$-type bond (NLMO 157) and a p-d $\pi$-type bond (NLMO 158). Furthermore, the $\mathrm{Ti}_{-} \mathrm{PMe}_{3}$ bond can be interpreted as a dative bond, with a major contribution (74\%) of sp-hybrid orbitals at the P PMe3 atom (NLMO 159). When evaluating the NLMO's of 5 (Table S12), it is immediately noticeable that these are very similar to those described beforehand for

3. The results from NBO-analysis were corroborated by quantum theory of atoms in molecules analysis (Figure S20-21) and electron localization function (ELF) analysis (Figure S22-S23) the latter also showing a dative $\mathrm{Ti}-\mathrm{PMe}_{3}$ bond and a lone pair of electrons at the P1 (3) and As1 (5) atom, respectively.
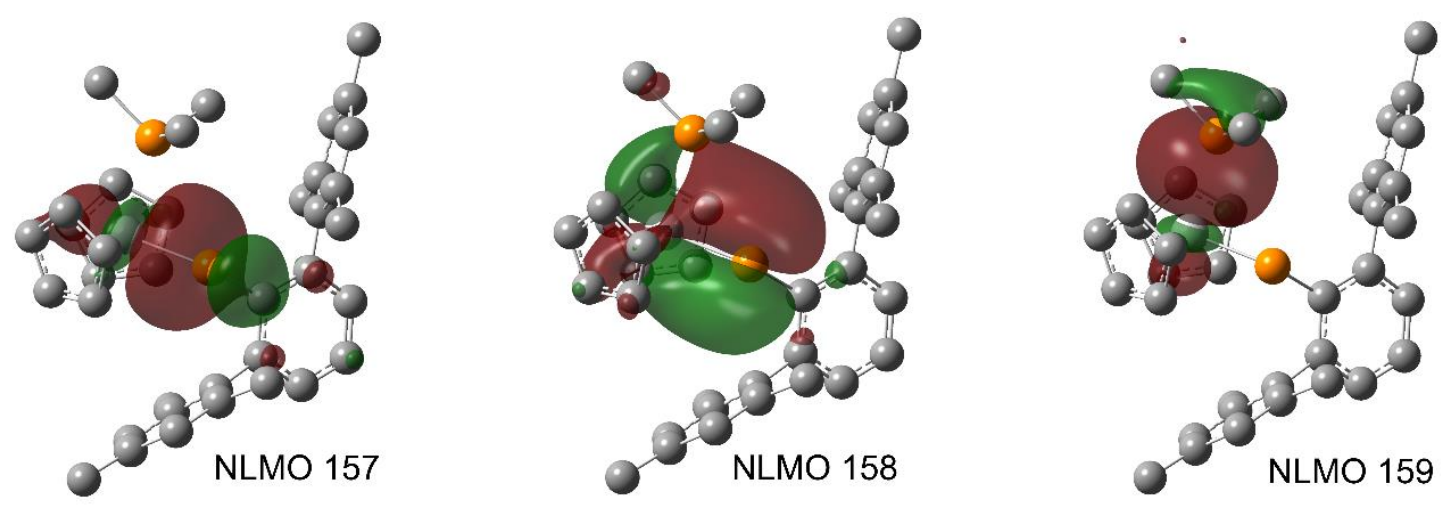

Figure 2. Representation of selected NLMOs of compound 3 (for the related NLMOs of $\mathbf{5}$ see Table S12). 
Furthermore, there is a dumbbell-shaped ELF between titanium and the phosphinidene $\mathrm{P}$ (3) or arsinindene As (5) atom, respectively, indicating a $\mathrm{Ti}=\mathrm{Pn}(\mathrm{Pn}=\mathrm{P}, \mathrm{As})$ double bond on the basis of this theory, which is further underlined by Wiberg Bind Indices of $1.73(\mathbf{3})$ and $1.72(\mathbf{5})$, respectively. However, both the NBO analyses and the ${ }^{13} \mathrm{C}-\mathrm{NMR}$ high field shift of the Cp substituents of 3 (104 ppm; c.f. $1 \delta=118$ ppm) indicate a possible delocalization of the $\mathrm{Ti}=\mathrm{Pn}$ bond resulting in an electron rich titanium center. ${ }^{39,40}$ With these results in mind, we next proofed the stability of the wave functions with respect to RHF/UHF or RKS/UKS instabilities, in order to analyse a potential biradical character of complexes $\mathbf{3}$ and $\mathbf{5}$. While the Kohn-Sham wave function showed no instabilities, the Hartee-Fock solution exhibited a low-lying, "brokensymmetry" open-shell singlet state. Therefore, we used the Complete Active Space $(\operatorname{CAS}(2,2))$ method $^{41,42}$ to obtain a multi-determinant open-shell singlet wave function, which potentially describes the bonding situation in $\mathbf{3}$ and $\mathbf{5}$ more precisely. This calculation determined the biradical character of 3 and $\mathbf{5}(\beta(\mathbf{3})=37 \% ; \beta(\mathbf{5})=40 \%)$ to be considerable. ${ }^{43}$ The contributions to the multi-determinant wave function are characterized by two determinants placing two electrons either in the formal HOMO $\left(\phi_{1}\right)$ or LUMO $\left(\phi_{2}\right)$ (Figure 3).

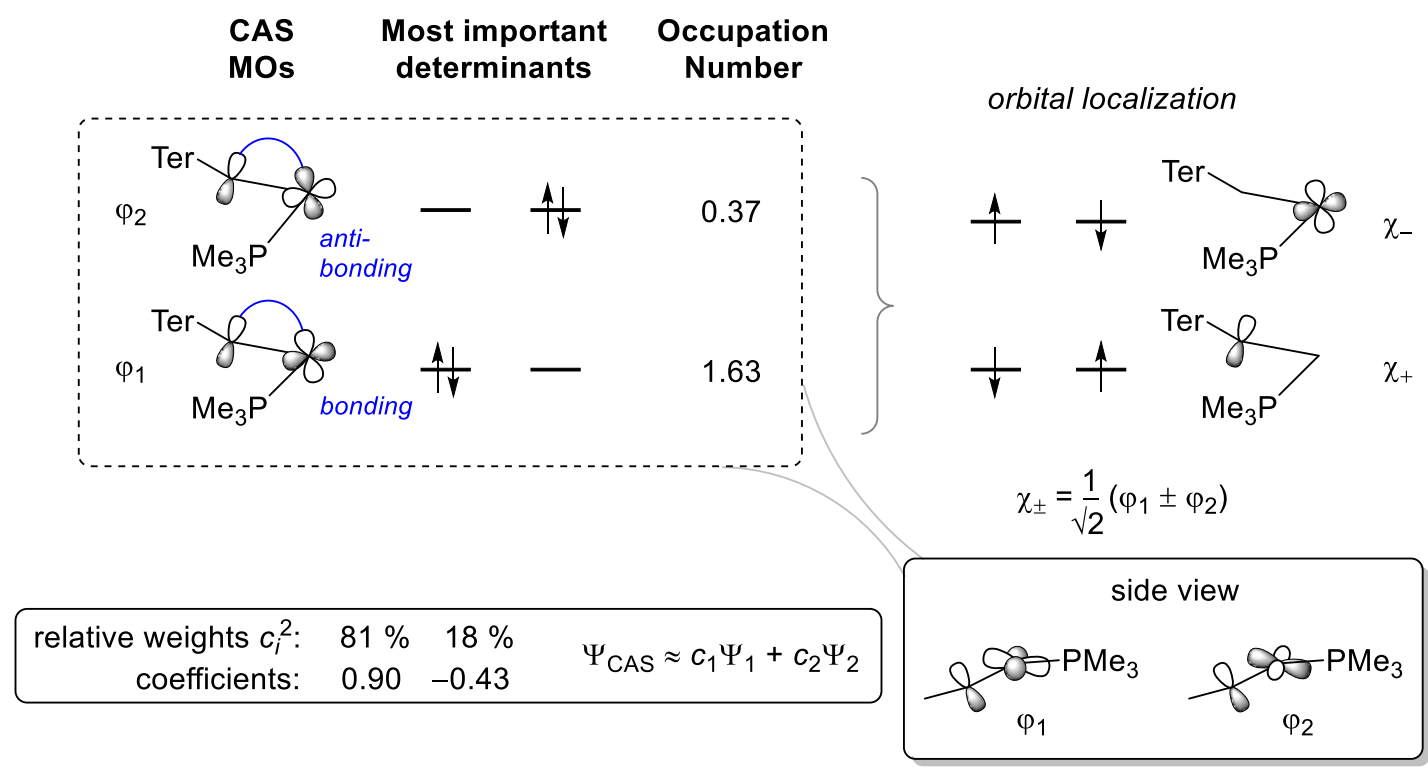

Figure 3. Schematic depiction of the active orbitals of $\mathrm{Cp}_{2} \mathrm{Ti}\left(\mathrm{PMe}_{3}\right) \mathrm{P}^{\mathrm{Mes}} \mathrm{Ter}$ (3) (CAS(2,2)/def2svpp). 
The singlet state is calculated to be the ground state $\left(\Delta E_{\mathrm{S}-\mathrm{T}}(\mathbf{3})=-106.2 \mathrm{KJ} \cdot \mathrm{mol}^{-1} ; \Delta E_{\mathrm{S} \text { - }}\right.$ $\left.\mathrm{T}(\mathbf{5})=-96.6 \mathrm{KJ} \cdot \mathrm{mol}^{-1}\right)$; i.e. the radical centres are strongly antiferromagnetically coupled. Consequently, the electronic structure can be understood as a complex between a formal $\mathrm{Ti}(\mathrm{III})$ fragment and an pnictogen-centred radical, whose "free" electrons are antiferromagnetically coupled and both complexes $\mathbf{3}$ and $\mathbf{5}$ show no indication for paramagnetically shifted NMR spectra (Figure 3, active orbitals and bonding in 3, for $\mathbf{5}$ see Figure S25).

In summary, the syntheses of the first titanocene phosphinidene and arsinidene complexes $\mathbf{3}$ and $\mathbf{5}$ are outlined, the latter being an elusive example with a titanium arsenic double bond. These compounds became available by employing [Cp $2 \mathrm{Ti}(\mathrm{btmsa})]$ and phospha- or arsa-Wittig, respectively. Based on this study, work is currently underway on evaluating the reactivity of the herein introduced pnictogen titanium complexes.

\section{Acknowledgements}

C. H.-J. thanks Prof. M. Beller for his support, and support by an Exploration Grant of the Boehringer Ingelheim Foundation (BIS) is acknowledged. We thank our technical and analytical staff, especially Dr. A. Spannenberg for her support regarding X-ray analysis. F. R. thanks Dr. Jonas Bresien for fruitful discussions about the computational results, the ITMZ at the University of Rostock for access to the Cluster Computer and especially M. Willert for technical support.

\section{Conflicts of interest}

There are no conflicts to declare. 


\section{Notes and References}

1. F. E. Hahn and M. C. Jahnke, Angew. Chem. Int. Ed., 2008, 47, 3122-3172.

2. M. Melaimi, M. Soleilhavoup and G. Bertrand, Angew. Chem. Int. Ed., 2010, 49, 8810-8849.

3. D. Munz, Organometallics, 2018, 37, 275-289.

4. M. Melaimi, R. Jazzar, M. Soleilhavoup and G. Bertrand, Angew. Chem. Int. Ed., 2017, 56, 10046-10068.

5. U. S. D. Paul and U. Radius, Eur. J. Inorg. Chem., 2017, 2017, 3362-3375.

6. A. H. Cowley, Acc. Chem. Res., 1997, 30, 445-451.

7. W. J. Transue, A. Velian, M. Nava, C. García-Iriepa, M. Temprado and C. C. Cummins, J. Am. Chem. Soc., 2017, 139, 10822-10831.

8. L. Liu, David A. Ruiz, D. Munz and G. Bertrand, Chem, 2016, 1, 147-153.

9. R. Waterman, Dalton Trans., 2009, 1, 18-26.

10. F. Mathey, Dalton Trans., 2007, 19, 1861-1868.

11. K. Lammertsma and Mark J. M. Vlaar, Eur. J. Org. Chem., 2002, 2002, 1127-1138.

12. F. Mathey, Angew. Chem. Int. Ed. in English, 1987, 26, 275-286.

13. H. Aktaş, J. C. Slootweg and K. Lammertsma, Angew. Chem. Int. Ed., 2010, 49, 2102-2113.

14. M. E. García, D. García-Vivó, A. Ramos and M. A. Ruiz, Coord. Chem. Rev., 2017, 330, 1-36.

15. G. Zhao, F. Basuli, U. J. Kilgore, H. Fan, H. Aneetha, J. C. Huffman, G. Wu and D. J. Mindiola, J. Am. Chem. Soc., 2006, 128, 13575-13585.

16. F. Basuli, J. Tomaszewski, J. C. Huffman and D. J. Mindiola, J. Am. Chem. Soc., 2003, 125, 10170-10171.

17. B. C. Bailey, J. C. Huffman, D. J. Mindiola, W. Weng and O. V. Ozerov, Organometallics, 2005, 24, 1390-1393.

18. J. D. Masuda, A. J. Hoskin, T. W. Graham, C. Beddie, M. C. Fermin, N. Etkin and D. W. Stephan, Chem. Eur. J., 2006, 12, 8696-8707.

19. J. D. Protasiewicz, Eur. J. Inorg. Chem., 2012, 2012, 4539-4549.

20. U. J. Kilgore, H. Fan, M. Pink, E. Urnezius, J. D. Protasiewicz and D. J. Mindiola, Chem. Commun., 2009, 30, 4521-4523.

21. U. Rosenthal, Organometallics, 2020, 39, 4403-4414.

22. A. Schumann, F. Reiß, H. Jiao, J. Rabeah, J.-E. Siewert, I. Krummenacher, H. Braunschweig and C. Hering-Junghans, Chem. Sci., 2019, 10, 7859-7867.

23. U. Rosenthal, V. V. Burlakov, P. Arndt, W. Baumann and A. Spannenberg, Organometallics, 2003, 22, 884-900.

24. M. Fischer, L. Vincent-Heldt, M. Hillje, M. Schmidtmann and R. Beckhaus, Dalton Trans., 2020, 49, 2068-2072.

25. P. Gupta, J.-E. Siewert, T. Wellnitz, M. Fischer, W. Baumann, T. Beweries and C. Hering-Junghans, Dalton Trans., 2021, 50, 1838-1844.

26. Experimental, computational, and details on the X-ray diffraction studies are included in the ESI. CCDC 2060154-2060157 contain the supplementary crystallographic data for this paper. 
27. Y. Masaaki, S. Takahiro and I. Naoki, Chem. Lett., 1988, 17, 1735-1738.

28. D. Wang, W. Ding, G. Hou, G. Zi and M. D. Walter, Chem. Eur. J., 2020, 26, 1688816899.

29. L. Yang, D. R. Powell and R. P. Houser, Dalton Trans., 2007, 9, 955-964.

30. M. Fischer, M. C. Wolff, E. del Horno, M. Schmidtmann and R. Beckhaus, Organometallics, 2020, 39, 3232-3239.

31. Z. Hou, T. L. Breen and D. W. Stephan, Organometallics, 1993, 12, 3158-3167.

32. P. Pyykkö and M. Atsumi, Chem. Eur. J., 2009, 15, 12770-12779.

33. R. C. Smith, P. Gantzel, A. L. Rheingold and J. D. Protasiewicz, Organometallics, 2004, 23, 5124-5126.

34. M. Fischer, S. Nees, T. Kupfer, J. T. Goettel, H. Braunschweig and C. HeringJunghans, J. Am. Chem. Soc., 2021, http://dx.doi.org/10.1021/jacs.1c00204.

35. J. B. Bonanno, P. T. Wolczanski and E. B. Lobkovsky, J. Am. Chem. Soc., 1994, 116, 11159-11160.

36. N. C. Mösch-Zanetti, R. R. Schrock, W. M. Davis, K. Wanninger, S. W. Seidel and M. B. O'Donoghue, J. Am. Chem. Soc., 1997, 119, 11037-11048.

37. M. K. Sharma, B. Neumann, H.-G. Stammler, D. M. Andrada and R. S. Ghadwal, Chem. Commun., 2019, 55, 14669-14672.

38. B. M. Gardner, G. Balázs, M. Scheer, F. Tuna, E. J. L. McInnes, J. McMaster, W. Lewis, A. J. Blake and S. T. Liddle, Nat. Chem., 2015, 7, 582-590.

39. F. Reiss, M. Reiss, J. Bresien, A. Spannenberg, H. Jiao, W. Baumann, P. Arndt and T. Beweries, Chem Sci, 2019, 10, 5319-5325.

40. E. P. Beaumier, C. P. Gordon, R. P. Harkins, M. E. McGreal, X. Wen, C. Copéret, J. D. Goodpaster and I. A. Tonks, J. Am. Chem. Soc., 2020, 142, 8006-8018.

41. M. Klene, M. A. Robb, M. J. Frisch and P. Celani, J. of Chem. Phys., 2000, 113, 5653-5665.

42. N. Yamamoto, T. Vreven, M. A. Robb, M. J. Frisch and H. Bernhard Schlegel, Chem. Phys. Lett., 1996, 250, 373-378.

43. E. Miliordos, K. Ruedenberg and S. S. Xantheas, Angew. Chem. Int. Ed., 2013, 52, 5736-5739. 